\section{B A Institute of \\ YK Business Administration \\ 六下 \\ Karachi \\ Leadership and Ideas for Tomorrow}

Business Review

Volume 6 Issue 2 July-December 2011

7-1-2011

\title{
An information technology (IT) based approach for enhancing prompt and effective post-disaster reconstruction
}

Faisal Manzoor Arain

Southern Alberta Institute of Technology, Canada

Follow this and additional works at: https://ir.iba.edu.pk/businessreview

Part of the Databases and Information Systems Commons

\section{(c) (1)}

This work is licensed under a Creative Commons Attribution 4.0 International License.

\section{Recommended Citation}

Arain, F. M. (2011). An information technology (IT) based approach for enhancing prompt and effective post-disaster reconstruction. Business Review, 6(2), 67-79. Retrieved from https://doi.org/10.54784/ 1990-6587.1193

This article is brought to you by iRepository for open access under the Creative Commons Attribution 4.0 License and is available at https://ir.iba.edu.pk/businessreview/vol6/iss2/5. For more information, please contact irepository@iba.edu.pk. 


\title{
ARTICLE
}

\section{An Information Technology (IT) Based Approach For Enhancing Prompt And Effective Post-disaster Reconstruction}

\author{
Faisal Manzoor Arain \\ Southern Alberta Institute of Technology, Canada
}

\begin{abstract}
Information technology (IT) has become strongly established as a supporting tool for many professional tasks in recent years. One application of IT, namely the knowledge management system, has attracted significant attention requiring further exploration as it has the potential to enhance processes, based on the expertise of the decision-makers. A knowledge management system can undertake intelligent tasks in a specific domain that is normally performed by highly skilled people.

Typically, the success of such a system relies on the ability to represent the knowledge for a particular subject. Post-disaster reconstruction and rehabilitation is a complex issue with several dimensions. Government, nongovernmental and international organizations have their own stakes in disaster recovery programs, and links must be established among them, as well as with the community. Concerning the post-disaster reconstruction scenario, the most significant factor is the prompt decision making based on best possible information available. Effective post-disaster response is crucial and lies at the heart of disaster management agency in almost every cautious country around the globe.
\end{abstract}

This paper presents a theoretical framework leveraging on IT for developing a knowledge management approach for enhancing prompt and effective post-disaster reconstruction. The conceptual model consists of two main IT based components of knowledge management system, i.e., a knowledgebase and a decision support shell for making more informed decisions for effective and timely response in post-disaster reconstruction scenario. The system is expected to assist in improving reconstruction project processes, coordination and team building process because the most likely areas on which to focus to reduce unwise decision can be identified during the early stage of the post-disaster scenario. Tapping on the past experiences of post-disaster scenarios, the knowledge management system provides a wealth of pertinent and useful information for decision makers and eventually enhance collaborative venture.

Development is a dynamic process, and disasters are thopportunities to vitalize and/or revitalize this process, especially to generate local economies, and to upgrade livelihood and living condition. The success of the reconstruction phases i.e., rescue, relief and rehabilitation is mainly dependent on the availability of efficient project team and timely information for informed decision. By having the knowledge-base and a systematic way to make well-informed decisions, the efficiency of project team and 
the likelihood of strong coordination and eventually project success should increase. The study would assist professionals from academia and industry involved in research and reconstruction projects. The system would be helpful for them to take proactive measures for reducing uninformed decisions related to team building and project coordination processes undertaken by disaster management agencies. Professionals need to work in close cooperation with each other to give rise to a better and more efficient system. Hence, the study is valuable for all the professionals involved with research and development.

Keywords: Knowledge-base, Management, Reconstruction, Decision Making, IT.

\section{Introduction}

Post-disaster reconstruction and rehabilitation is a complex issue with several dimensions. Many professionals in both fields tend to focus more on planning and immediate response and have only recently begun to consider the requirements and opportunities inherent in long-term mitigation and reconstruction (Vale and Campanella, 2005). The complex and multi-faceted processes of post-disaster recovery and reconstruction extend well beyond the immediate period of restoring basic services and life support infrastructure. While immediate restoration of services can be a matter of weeks, full recovery can stretch out 10-15 years (Pelling, 2003). Government, non-government, international organizations have their own stakes in disaster recovery programs, and links must be established among them, as well as with the community as shown in Figure 1(Shaw et al., 2003). In other words, a post-disaster rehabilitation and recovery programs should be seen as the opportunities to work with communities and serve local needs. Relief and development often lead to burdens on the recipient government, and also often fail to serve the actual purpose and to reach the people in needs.

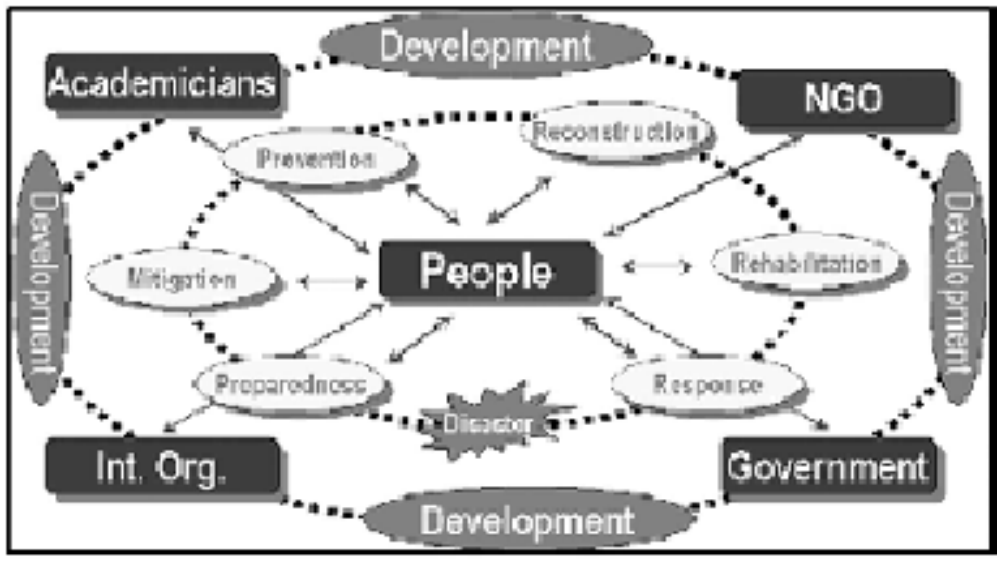

Figure 1 Disaster cycle, development process and stakeholder involvement [Source: adapted from Shaw et al., 2003]

Environmental management professionals are now concentrating more on the sustainability of environmental quality and environmental improvement; emergency managers and planners are re-focusing their efforts more on the survivability of systems, organizations, and communities (Vale and Campanella, 2005). Sustainability and survivability are, in truth, 
two aspects of the same concept, namely: how to encourage and achieve continual improvement in ecosystems, the built environment, and human society (Pellow and Brulle, $2005)$. Both environmental management and emergency management have much to contribute to, and to gain from, the planning and implementation of post-disaster reconstruction.

Development is a dynamic process, and disasters are the opportunities to vitalize and/or revitalize this process, especially to generate local economies, and to upgrade livelihood and living condition. Shaw and Sinha (2003) suggested the idealized level of involvement of different stakeholders after the disaster as shown in Figure 2. The standard time frame of rescue, relief and rehabilitation are defined as short term, long term and longer term respectively.

As shown Figure 3, rehabilitation process has three major stages i.e., Principles and Planning, Implementation and Ensuring Sustainability (Shaw and Sinha, 2003). Rehabilitation was not just a short term, gap filling exercise. There is a huge amount of information flows between professionals involved in the rehabilitation project (Arain, 2005). The process initiate by setting up the basic principles for planning the rehabilitation intervention. The process has to be participatory, with a gradual increase in the involvement of the community. Implementation stage of the post-disaster reconstruction project consisted of three steps i.e., need asses sment, capacity building, and implementation. The effort initiated by the professionals involved in post-disaster reconstruction project needed to be sustainable long after the interventions were over. In effect, intervention should be designed to ensure that the community was able to take care of its development needs and was resilient against future disasters. For this, strengthening local institutions is necessary (Shaw and Sinha, 2003).

\begin{tabular}{|l|c|c|c|}
\hline \multirow{2}{*}{ STAKEHOLDERS } & \multicolumn{3}{|c|}{ INTERVENTION } \\
\cline { 2 - 4 } & RESCUE & RELIEF & RECOVER \\
\hline
\end{tabular}

\begin{tabular}{|c|}
\hline GOVERNMENT \\
\hline NON-GOVERN \\
\hline INTERNATION \\
\hline COMMUNITY \\
\hline
\end{tabular}

Figure 2 Idealized level of interventions of different stakeholders after disaster (Size of the box is proportional to the level of interventions) [Source: adapted from Shaw and Sinha, 2003]

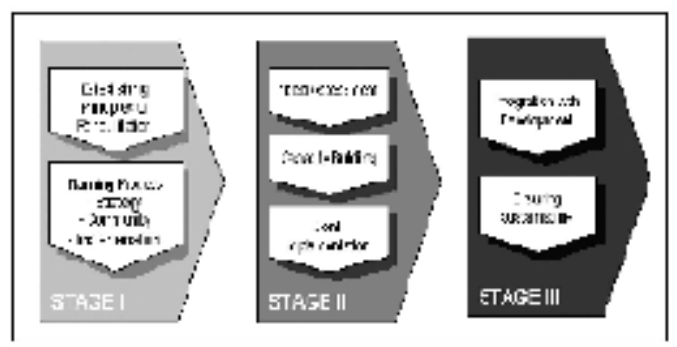

Figure 3 Different stages of recovery process in a post-disaster management scenario 
[Source: adapted from Shaw and Sinha, 2003]

Increasing discussions and debates within disaster mitigation interest groups have raised questions regarding the practicality of adopting developmental approaches to disaster reconstruction (Ahmed, 2005). The chaos surrounding the disaster period following a disaster could easily lead to short-term and hasty decisions adversely affecting community's ability to achieve sustainable, long term reconstruction goals (Hidellage and Pullenayegem, 2008). To minimize occurring of these unwise decisions, it is important to plan proactively for post-disaster restoration in order to provide general guidance for decision-makers and a framework for the professionals involved in reconstruction process (Iglesias, 2007). For proactive plans and decisions, an integrated approach is required that may empower to implement the developed reconstruction strategy and monitor its results and progress.

Reconstruction usually requires building a large number of shelters within a shortest possible time using available limited resources (Ahmed, 2008). Practical action discerned early in the rebuilding phase that there was dire need to ensure construction quality, have competent construction tradesmen, minimize use of construction material and use construction technology that is readily replicable (Hidellage and Pullenayegem, 2008).

The recent sudden increase of natural disasters has taught many valuable lessons (Iglesias, 2007). Unfortunately, the need for preparedness is greater than ever before, given the increasing frequency and worsening intensity of weather-related storms and the escalation of technological threats. No geographical area is immune or protected from the threat of emergencies and disasters. The importance of proactive approach in responding to a disaster struck scenario in term of learning from past projects cannot be overstated. Pre-planning with local public safety and emergency response agencies can decrease confusion when a jobsite incident occurs (Ahmed, 2008). A quick response due to proper pre-planning and preparedness can expedite saving lives and rehabilitation process.

Numerous researches suggested that factors about IT considerations and communications continuity should be defined and stored because the link between a source and consequence is mainly determined by these factors (Shaw and Sinha, 2003; Arain, 2005; Arain and Low, 2006a; Ahmed, 2008). As the decisions need to be made in short time, the availability of prompt and useful information has the highest potential to affect future decisions (Arain and Low, 2006b). Lessons learnt with respect to those rather controllable factors may result in better management of emergency risks in the forthcoming projects. Further, it is clear that the major benefit of the approach is not the development of a fit-for-all emergency preparedness plan but rather capitalizing on past experience of similar projects and a customizable strengths and weaknesses based emergency preparedness plan which is dynamic in nature (Cameron et al., 2004; Arain and Low, 2006b).

Information is a pre-requisite in all research and development activities and can be regarded appropriately as the life-blood within which business interactions unfold (Low, 1993). Knowledge acquisition is the major bottleneck in the industry (Skibniewski, et al., 1997). In view of the transfer and acquisition of knowledge and experience, a DSS can help to conserve the knowledge and experience and make these more widely, easily and quickly available for assisting in the decision making process (Arain, 2007a). The decision aid can also facilitate the knowledge acquisition process once it has acquired the necessary knowledge and experience and transferred the se into a usable form (Arain and Low, 2007a). The decision aid also enables the professionals to consider more factors that can affect project team formation during the decision making process, conduct more thorough decision processing, and influence their preferred information (Poe, et al., 1998). 
Information technology (IT) has become strongly established as a supporting tool for many professional tasks in recent years. One application of IT, namely the knowledgebase system, has attracted significant attention requiring further exploration as it has the potential to establish the close coordination between construction processes, based on the expertise of the decision-makers (Low, 1996). A knowledge-base is a system that can undertake intelligent tasks in a specific domain that is normally performed by highly skilled people (Arain and Low, 2007b). Typically, the success of such a system relies on the ability to represent the knowledge for a particular subject. Concerning the post-disaster reconstruction scenario, the most significant factor is the prompt delivery of materials and pertinent team building based on best possible information available.

Management decides and implements the ways and means to effectively and efficiently utilize human and non human resources to reach predetermined objectives (Low et al., 2007). Project managers are expected to marshal resources to complete a fixed-life project on time, on budget, and within specifications. Project managers are the direct link to the customer and must manage the interface between customer expectations and what is feasible and reas onable (Arain, 2007b). They provide direction, coordination, and integration to the project team, which is often made up of part time participants loyal to their functional departments. Project managers must ensure that appropriate trade-offs are made between the time, cost and performance requirements of the project (Low, 1996). Unlike their counterparts, project managers generally posses only rudimentary technical knowledge to make such decisions. Instead, they must orchestrate the completion of the project by inducing the right people and resources, at the right time, to address the right is sues and make the right decisions. Certainly, resource optimization for successful project management is a unique and challenging task (Arain, 2007b).

There are always more actions required and project proposals than there are available resources. The priority system needs to prioritize the scenarios that best contribute to the teams' objectives, within the constraints of the resources available (Arain, 2007a). If all emergency activities and their respective resources are computer scheduled, the feasibility and impact of adding a new project to those in process can be quickly assessed. With this information the project team will add a new project only if resources are available and formally committed to that specific project or through resource optimization skills and techniques.

As mentioned earlier, reconstruction projects are complex because they involve many resources and variables (Arain and Low, 2007b). They usually have range of short to long duration, various uncertainties, and complex relationships among the participants. The integration of resource allocation knowledge and experience at the early design phase provides the best opportunity to improve overall project performance (Arain and Low, 2006a). From the outset, project strategies and philosophies should take advantage of lessons learned from past similar projects.

Learning from the past projects is very important because the professionals could improve and apply their experience in the future (Turban, 1990; Arain, 2008). No projects can be executed without people. Not even the purest, technical project. And the more the world moves into the knowledge society, the more obvious it is that managing people in projects is equally important as managing the technical and financial side. But this soft people approach must not be so focused that one forgets that projects after all is to come up with hard technical and financial solutions to a problem (Parker, 1985). 
Today, lessons learned are that we should not let the pendulum swing too much to any one side. If it swings, it must do so in harmony with which we happen to be in the lifetime of the project we are working on. In the first place, the development phase and the type and the size of the project should affect the pendulum's amplitude and direction. Next it is clearer now that this undulation of the pendulum is as much a responsibility of the project manager as it is a random phenomenon, desirable or undesirable. In the future, modern project management will probably have to incorporate this responsibility to ensure that the swings - or leadership - of the pendulum are both sensible and beneficial (Arain and Low, 2008).

It became vital, in consequence, to strengthen the relations between the people taking part in the project, to ensure that they understand and accept the goal, communicate sensibly with the project manager and view the system of the project to be an important support without being a straightjacket (Shaw and Sinha, 2003). There are other types of "tools" for this purpose, i.e., varied selection of reward and punishment systems. The project manager should be familiar with them too, and be able to apply them sensibly and creatively. Or to say it differently, it is just as important to spend efforts on the cultural aspect as it is to care for the systems side for better project resource allocation and optimization (Ahmed, 2005).

Considering significance of the team approach especially during post-disaster scenario, the project leader must be able to encourage the team to make a contribution, within reas onable limits, and understand how to improve relationships among them (Ashworth, 1999). The leader can use psychological and financial mechanisms here, and weigh up carefully what might be considered a good reward - or punishment - in each individual case. A reward need not to be understood in terms of wages alone, but as a sensible bonus system or the allocation of stimulating tasks with a view to practicing and developing the team's knowledge and skills. Punishments can mean taking people off tasks they are not performing technically satisfactorily, if they are making a nuisance of themselves, or in other ways causing problems (Dyche, 2000).

Post-disaster reconstruction and rehabilitation is a complex issue with several dimensions. Government, nongovernmental and international organizations have their own stakes in disaster recovery programs, and links must be established among them, as well as with the community. Concerning the post-disaster reconstruction scenario, the most significant factor is the prompt decision making based on best possible information available (Ahmed, 2005). Effective post-disaster response is crucial and lies at the heart of disaster management agency in almost every cautious country around the globe.

Development is a dynamic process, and disasters are the opportunities to vitalize and/or revitalize this process, especially to generate local economies, and to upgrade livelihood and living condition. The success of the reconstruction phases i.e., rescue, relief and rehabilitation is mainly dependent on the availability of efficient project team and timely information for informed decision (Arain and Low, 2008). It is suggested that a knowledge management system may assist in improving reconstruction project processes, coordination and team building process because the most likely areas on which to focus to reduce unwise decision can be identified during the early stage of the post-disaster scenario (Arain and Low, 2006a). Tapping on the past experiences of post-disaster scenarios, the knowledge management system provides a wealth of pertinent and useful information for decision makers and eventually enhance collaborative venture. By having the knowledge-base and a systematic way to make well-informed decisions, the efficiency of project team and the likelihood of strong coordination and eventually project success should increase (Arain, 2007). 


\section{Reason for poor value in post-disaster reconstruction in industry}

Good quality information lies at the heart of the correct definition of any project, the awareness of which will usually fall within the responsibility of a client organization. The project awareness stage may lead to a development stage within the client organization, which is the key stage to implement VM (Kelly, et al., 2004).

Parker (1985) and Ashwoth (1999) identified the most significant causes of poor value in projects. These causes included lack of information, decisions based on wrong beliefs, habitual thinking, negative attitudes, reluctance to seek advice, shortage of time, changing technology, lack of a yardstick for measuring value, old specifications, and poor human relations. Furthermore, Arain et al. (2004) argued that the most important factor for achieving good value in projects was timely and useful information.

Although each construction project is unique based on its special conditions, professionals can still obtain certain useful information from past experience. Having timely and useful information, the professionals would be able to better ensure that their project goes smoothly without making gratuitous mistakes, and it should be helpful to improving the performance of the project (Arain and Low, 2006a).

Every construction project requires sufficient information regarding the predetermined project objectives (Iglesias, 2007). Computerized Decision Support System (DSS) can be used by project participants to help make more informed decisions regarding the management of detrimental changes in reconstruction projects by providing access to useful, organized and timely information (Arain and Low, 2006b).

\section{IT based approach for enhancing prompt and effective post-disaster reconstruction}

An important key to the success of IT is the ability to provide users with the right information at the right time (Turban and Meredith, 1994). The alternatives amongst which a decision must be made can range from a few to a few thousand. The decision maker needs to narrow the possibilities down to a reasonable number (Turban, 1990). Decision support, such as a selective information retrieval system can help with this task. Computers can evaluate alternatives, especially when the alternatives can be presented in numerical terms. Even when this is not the case, the computer can assist the decision maker in presenting the alternatives in a form that facilitates the decision (Arain and Low, 2006a).

Many management decisions need to be made within a time cons traint especially in the post-disaster reconstruction case. The current technological progress does not allow the complete computerization of all the managerial functions or the creation of a tool capable of carrying out automatically all the required management decisions. To ensure the success of this important management function, human involvement in this process remains essential. Thus the DSS approach for this kind of application seems to be the most natural idea (Miresco and Pomerol, 1995). A knowledge-base is a system that can undertake intelligent tasks in a specific domain that is normally performed by highly skilled people (Miresco and Pomerol, 1995; Cameron, et al., 2004). Typically, the success of such a system relies on its ability to represent the knowledge for a particular subject.

Rapid access to remote information such as consulting experts or providing a group decision meeting is often necessary for making informed decisions (Dyche, 2000; Arain, 2007a). The sophisticated analyses that a knowledge-base can provide becomes an important 
factor in making good and valuable decisions. If professionals have a knowledge-base established based on past similar projects, it would assist the professional team to plan effectively before starting a reconstruction project.

\section{Basis for the development of the knowledge-base}

The fundamental idea of any effective management system is to anticipate, recognize, evaluate, resolve, control, document, and learn from past projects in ways that support the overall viability of the project (Arain and Low, 2006b). The professionals can improve and apply their experience in future projects; hence learning from the past projects is imperative. This would help the professionals in taking proactive measures for reducing potential mistakes.

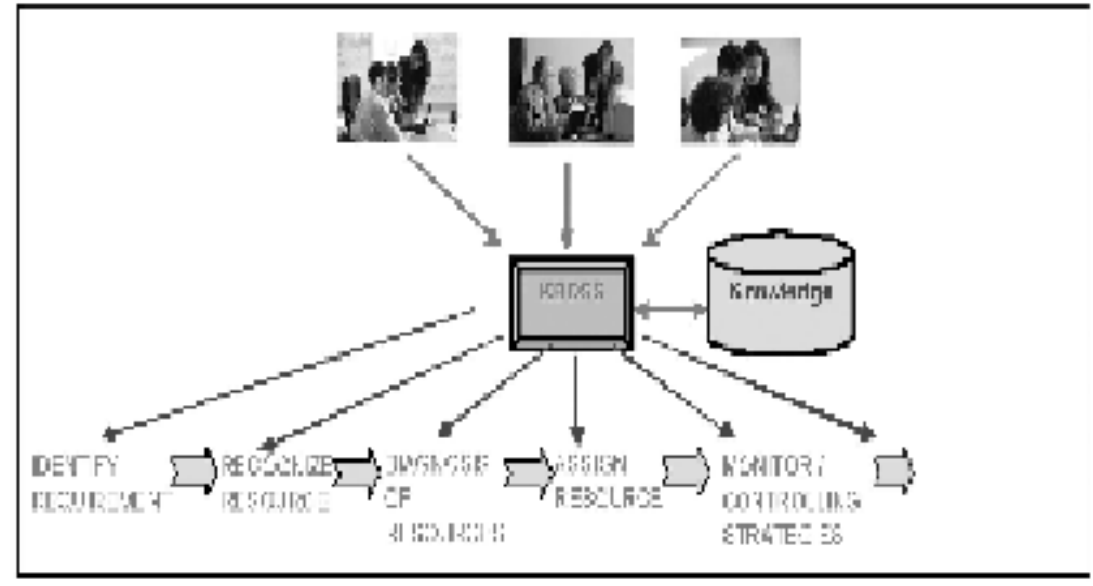

Figure 1 Basis for developing IT based system for enhancing management of recons truction projects

As shown in Figure 1, the basis for developing a model for the knowledge-base for enhancing prompt response and coordination in post-disaster reconstruction projects was to utilize a knowledge-base platform for sharing knowledge for effective management (Arain and Low, 2006b). The project team would be able to carry out the structured process based on the six effective management principles. The most integral part of this model is the knowledge-base that assists in carrying out the process for management. Here it is therefore important to understand that the knowledge-base is not designed to make decisions for users, but rather it provides pertinent information in an efficient and easy-to-access format that allows users to make more informed decisions. Although this system does not try to take over the role of the human experts or force them to accept the output of the system, it provides more relevant evidence and facts to facilitate the human experts in making well-informed final decisions. In providing a systematic way to share knowledge and manage through the knowledge-base, the efficiency of project teams and the likelihood of project success would be enhanced (Turban and Aronson, 2000).

Like any building project, every reconstruction project involves a multi-player environment and represents a collaborative effort among specialists from various independent disciplines. The knowledge-base can assist managers in making strategic decisions by presenting useful information and interpretations for various alternatives. The knowledge- 
base would be capable of providing interpretation of knowledge based on the rule-based reasoning $(\mathrm{RBR})$ approach. The system can be used by project participants to help make more informed decisions regarding the management of project resources by providing access to pertinent and timely information. This would eventually assist professionals in improving chances of successful completion of projects because the potential lack of coordination issues can be identified at the early stage of team development when the impact of change is not severe.

During the project phases, in order to take remedial actions for any lack of coordination issues in the project, project managers often need timely information and analysis reports to assist in making more informed and precise decisions (Arain and Low, 2006a). It was found that in the course of most of the reporting and analys is activities, time was spent on collecting data from various systems before the analysis could be made. Project managers usually want and need more information for making decisions, but analysts can provide only minimal information at high costs within the desired time frame (Dyche, 2000). In order to provide information for predicting patterns and trends more convincingly and for analyzing and developing an effective project team more efficiently, a knowledge-base designed for this particular purpose was needed.

Considering the issues mentioned above, a knowledge-base is proposed for developing effective project teams and managing reconstruction projects in an efficient way. An important role of a knowledge-base is to provide useful information for users to analyze scenarios and to make informed decisions. The main components of the knowledge management system are shown in Figure 2. As presented in Figure 2, the data was collected from various sources i.e., organizations, project documents, site data, academia source documents and peers evaluation documents. This data was stored in a database. From the database, the data was sieved through an inference engine for developing the knowledge-base. Eventually, the knowledge-base provided decision support to the project teams for making more informed decisions for effective selection of project teams and successful management of reconstruction projects.

The knowledge-base would contain pertinent information for post-disaster reconstruction projects. The system would be able to present detail information about the resources utilized; management decisions made, changes made during project implementation and project teams worked on similar reconstruction projects in the past. Furthermore, the system would present the available pool of experts in the academia and industry. The filtered knowledge and analyses provided by the knowledge-base would as sist in selecting appropriate expert teams, resources, approval processes, and prioritizing activities based on past experiences in similar projects. The knowledge-base would also be capable of storing the feed back on the ongoing projects and carry out analyses on the available information and present results for decision making process by the concerned professionals. 


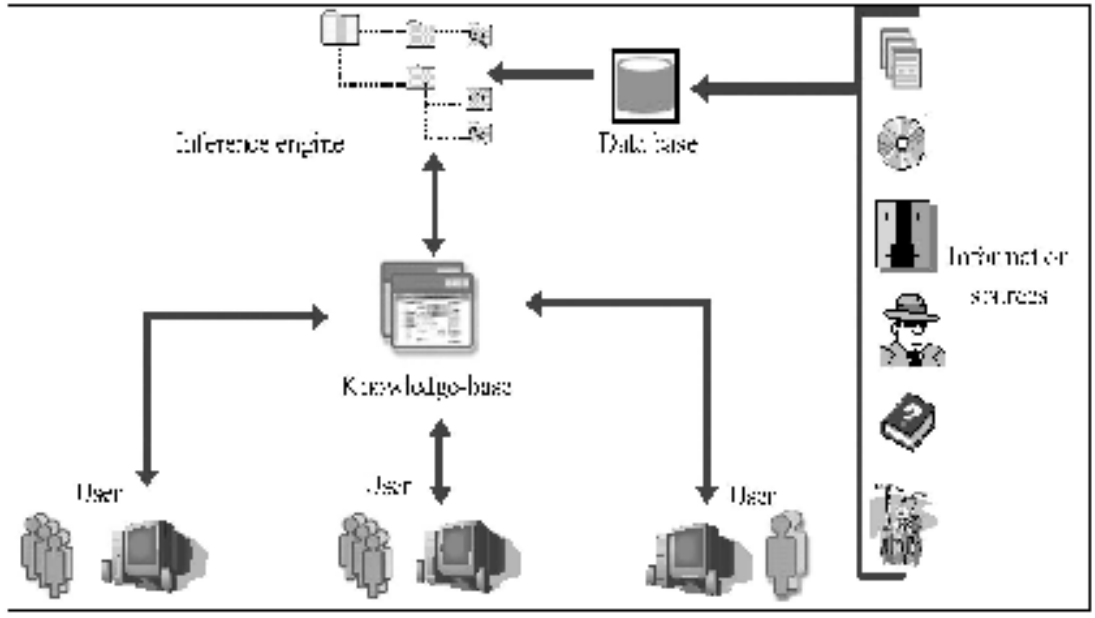

Figure 2 The main components of a knowledge management system

The knowledge-base can be developed in the MS Excel environment using numerous macros for developing the user-interface that carry out stipulated functions. These are incorporated within a controls selection shell. The graphical user interface (GUI) as sists users in interacting with the system at every level of the knowledge management system. In addition, the GUI and inference engine will maintain the compatibility between layers and the decision shell. System access and updating rights will be maintained by the program administrator to maintain control of information flow in the system. The knowledge management system provides an extremely fast response to the queries based on rule-based reasoning (RBR). As mentioned earlier, the system would be capable of displaying information pertinent to resources, reconstruction strategies, designs, expertise available and their relevant in-depth details, a variety of filtered knowledge, and various analyses of the knowledge available. The knowledge-base is able to assist project managers by providing accurate and timely information for decision making, and a user-friendly system for analyzing the present pool of human resource or experts in a particular area and selecting the best possible team, resources, materials, and designs for carrying out post-disaster reconstruction projects.

Moreover, the system is also intelligently capable of organizing, computing, and updating valuable information in all the layers automatically with every new project added. The user-interface assists in updating the system with new information on every level of the knowledge-base. The information and various filters that can be applied to the knowledgebase developed may as sist the professionals in learning from past projects for enhancing the chances of successful implementation of reconstruction projects.

\section{Conclusions}

Although every project has its own specific condition, professionals can still obtain certain useful information from past experience. This information will enable professionals to better ensure that their project goes smoothly without making unwarranted mistakes, and it should be helpful to improving the performance of the post-disaster reconstruction projects. A knowledge-base is a system that can undertake intelligent tasks in a specific domain that is normally performed by highly skilled people. Typically, the success of such a system 
relies on the ability to represent the knowledge for a particular subject. Post-disaster reconstruction and rehabilitation is a complex is sue with several dimensions. Government, nongovernmental and international organizations have their own stakes in disaster recovery programs, and links must be established among them, as well as with the community. Concerning the post-disaster reconstruction scenario, the most significant factor is the prompt and pertinent team building, resource allocation, materials selection, and shelter designs based on best possible information available. Useful and timely information lies at the heart of successful project management of any construction project. Effective postdisaster response is crucial and lies at the heart of disaster management agency in almost every cautious country around the globe.

Learning from the past projects is very important because the professionals could improve and apply their experience in the future. No projects can be executed without people. Not even the purest, technical construction project. And the more the world moves into the knowledge society, the more obvious it is that managing people in projects is equally important as managing the technical and financial side. But this soft people approach must not be so focused that one forgets that projects after all is to come up with hard technical and financial solutions to a problem. The success of the reconstruction phases i.e., rescue, relief and rehabilitation is mainly dependent on the availability of efficient project team and timely information for informed decision.

This paper presents a theoretical framework leveraging on IT for developing a knowledge-base for enhancing prompt and effective post-disaster reconstruction. The conceptual model consists of two main IT based components, i.e., a knowledge-base and a decision support shell for making more informed decisions for effective management of post-disaster reconstruction projects. The system is expected to assist in improving project coordination and team building process because the most likely areas on which to focus to reduce unwise decision can be identified during the early stage of the reconstruction project.

Tapping on the past experiences of post-disaster scenarios, the knowledge management system provides a wealth of pertinent and useful information for decision makers and eventually enhance collaborative venture. By having the knowledge-base and a systematic way to make well-informed decisions, the efficiency of project team and the likelihood of strong coordination and eventually project success should increase. The study would assist professionals from academia and industry involved in research and reconstruction projects. The system would be helpful for them to take proactive measures for reducing uninformed decisions related to team building and project coordination processes undertaken by disaster management agencies. Professionals need to work in close cooperation with each other to give rise to a better and more efficient system. Hence, the study is valuable for all the professionals involved with research and development.

\section{References}

Ahmed, K.I. (2005) Final Progress Report: Family Shelter. Disaster Relief and Recovery Facility, UNDP, Dhaka.

Ahmed, K.I. (2008) Challenges and opportunities of post-disaster shelter reconstruction: The Asian context, Proceedings of the 4th International $i$-Rec Conference, New Zealand, pp. $144-153$.

Arain, F.M. (2005) Potential barriers in management of refurbishment projects, Journal of Independent Studies and Research, 3(1), pp. 22-31. 
Arain, F.M. (2007a) School building design improvement through an IT based system, Proceedings of the International Research Symposium (SCRI) on 26th and 27th March 2007, University of Salford, England, pp. $39-61$.

Arain, F.M. (2007b) Critical success factors of project management practices in Pakistan construction industry, Construction Information Quarterly, Journal of the Chartered Institute of Building, CIQ Paper No. 224, 9(4), pp. 179 - 185.

Arain, F.M. (2008) Prime opportunity to learn about change, Construction Information Quarterly (CIQ), Journal of the Chartered Institute of Building, 10(1), pp. 25 - 26.

Arain, F.M. and Low, S.P. (2006a) A framework for developing a knowledge-based decision support system for management of variations in institutional buildings, Journal of Information Technology in Construction (ITCon), Special Issue Decision Support Systems for Infrastructure Management, 11(1), pp. 285-310.

Arain, F.M. and Low, S.P. (2006b) Knowledge-based decision support system for management of variation orders for institutional building projects, Automation in Construction, 15(1), pp. 272-291.

Arain, F.M. and Low, S.P. (2007a) Strategic management of changes in educational building projects: A timeline-based checklist approach, Proceedings of the 5th International Conference on Construction Project Management (ICCPM/ICCEM) on 1-2 March 2007, Singapore, pp. $1-15$.

Arain, F.M. and Low, S.P. (2007b) Modeling for management of variations in building projects, accepted for publication in Engineering, Construction and Architectural Management, $14(5)$, pp. $420-433$.

Arain, F.M. and Low, S.P. (2008) Change Management System (CMS): Project change management experience from Singapore construction industry, Proceedings of the CRC for Construction Innovation's Third International Conference - Clients Driving Innovation: Benefiting from Innovation, Gold Coast, Australia, pp. $1-26$.

Arain, F.M., Assaf, S. and Low, S.P. (2004) Causes of discrepancies between design and construction, Architectural Science Review, 47(3), pp. 237-249.

Ashworth, A. (1999) Cost Studies of Buildings, 3rd Ed., Addison Wesley Longman Ltd., England.

Cameron, I., Duff, R. and Hare, B. (2004) Integrated Gateways: Planning out Health and Safety Risk. Research Report 263, Glasgow Caledonian University, UK.

Dyche, J. (2000) E-Data Turning Data into Information with Data Warehousing. AddisonWesley, Reading, UK.

Hidellage, P.V. and Pullenayegem, V. (2008) Adapting strategies to meet needs in postdisaster reconstruction, Proceedings of the 4th International $i$-Rec Conference, New Zealand, pp. $21-31$.

Iglesias, G. (2007) Promoting safer house construction through CBDRM: Community 
designed safe housing in post-Xangsane Da Nang City, Safer Cities, 19(2), pp. 1-8. Kelly, J., Male, S., and Graham, D. (2004) Value Management of Construction Projects, Blackwell Science Inc., Malden, MA, USA.

Low, S. P. (1996) The management of large-scale upgrading programmes for public housing in Singapore", Property Management, 14(4), 27-32.

Low, S.P. (1993) Marketing Research for the Global Construction Industry, Singapore University Press, National University of Singapore, Singapore.

Low, S.P., Benny, R., Arain, F.M. and Susan, S. (2007) Analyzing construction-related market trends in APEC countries using GIS, Business Review, 2(2), pp. 29 - 47.

Miresco, E.T. and Pomerol, J.C. (1995) A knowledge-based decision support system for construction project management, Proceedings of the Sixth International Conference on Computing in Civil and Building Engineering, (2), pp. 1501-1507.

Parker, D. (1985) Value Engineering Theory. The Lawrence D. Miles Value Foundation, Washington.

Pelling, M. (2003) The Vulnerability of Cities: Natural Disasters and Social Resilience. Earthscan Publications, London.

Pellow, D.N. and Brulle, R.J. (2005) Power Justice and the Environment: A Critical Appraisal of the Environmental Justice Movement. The MIT Press, Cambridge MA.

Poe, V., Klauer, P. and Brobst, S. (1998) Building A Data Warehouse for Decision Support, Prentice Hall, Upper Saddle River, New Jersey.

Shaw R. and Sinha R. (2003) Towards sustainable recovery: future challenges after the

Gujarat earthquake, India, Risk Management Journal, 5(1), pp. 35-51.

Shaw R., Gupta M. and Sharma A. (2003) Community recovery and its sustainability: lessons from Gujarat earthquake of India, A ustralian Journal of Emergency Management, 18(1), pp. 28-34.

Skibniewski, M., Arciszewski, T. and Lueprasert, K. (1997) Constructability analysis: machine learning approach. Journal of Computing in Civil Engineering, 11(1), pp. 8-16.

Turban, E. (1990) Decision Support and Expert Systems: Management Support Systems. (2nd edition) Macmillan, New York.

Turban, E. and Aronson J. (2000) Decision Support Systems and Intelligent Systems. (8th edition) Prentice Hall, Upper Saddle River, NJ.

Turban, E. and Meredith, J.R. (1994) Fundamentals of Management Science. (6th edition) Irwin, Burr Ridge, Illinois.

Vale, L.J. and Campanella, T.J. (2005) The Resilient City: How Modern Cities Recover From Disaster. Oxford University Press, New York. 